\title{
Videogames and Ideological Frames
}

\author{
Ian Bogost \\ The Georgia Institute of Technology
}

\begin{abstract}
Based on cognitive linguist George Lakoff's notions of metaphor and frame as the principle organizers of political discourse, this article offers an approach to analyzing political rhetoric in videogames intended to carry ideological bias. I then argue for 3 ways games function in relation to ideological frames-reinforcement, contestation, and exposition-through examples of political games (Tax Invaders), art games (Vigilance 1.0), and commercial games (Grand Theft Auto: San Andreas). I also offer thoughts on issues likely to arise from the hypothetical adoption of political frame and metaphor as design principles.
\end{abstract}

The 2004 U.S. presidential election renewed world citizens' recognition of an ideological polarization in U.S. politics. The American electoral college, combined with the lack of a viable third-party, only increased the apparent split. Massive, telecast electoral college maps displaying won states in red (Republican) and blue (Democrat) suggested a geographic divide to many Americans, with the west coast, northeast, and Great Lakes areas voting Democratic and the heartland and south Republican. Yet more detailed maps that showed county-by-county vote balance proved that the division runs even deeper (Vanderbei, 2004), with most counties appearing some shade of purple, a combination of "red votes" and "blue votes." In the aftermath of the election, Democrats acknowledged that their messages failed, just as Republicans recognized how much theirs succeeded. Juxtaposing American morality against British class rifts, some cite religion as the key issue dividing the presidential vote (Schifferes, 2004a). The left is now scrambling to develop a new strategy. Ideas are plentiful: Avoid candidates from the northeast (Wallsten \& Anderson, 2004), focus more strongly on domestic issues (Schifferes, 2004b), and seek better management (Marinucci, 2004). But two influential political theorists and cognitive linguists suggested that such superficial strategies will

Correspondence should be addressed to Ian Bogost, The Georgia Institute of Technology, School of Literature Communication and Culture, 686 Cherry Street, Atlanta, GA 30332. E-mail: ian.bogost@lcc.gatech.edu 
not move the political needle; instead, political success draws less from reality and more from representation.

Lakoff (1990) and Lakoff and Johnson (1980) suggested that metaphor is central to human understanding. Lakoff and Johnson (influenced by Levi-Strauss, Clifford Geertz, and Jean Piaget) argued that our conceptual systems are fundamentally shaped by cultural constructions. For Lakoff and Johnson, metaphor is not a fanciful language reserved for poets, but an active framework central to how we understand the world. For example, the two unpack our understanding of time as a commodity, showing how we relate our experience of time to monetary concepts of quantification (you are running out of time; is that worth the time?). Turning to politics explicitly, Lakoff (1996) argued that the most important consideration in political discourse is not how politicians respond to the "facts" of the external world, but how they conceptualize, or "frame" that world in their discourse about it. Lakoff argued that political frames in the contemporary United States reflect metaphors of family management - conservatives frame political issues as "strict fathers," whereas liberals frame them as "nurturing parents" (p. 63). A self-professed liberal, Lakoff (2004) argued that if the left wants to regain political credibility, they need to start crafting their political speech with an understanding of liberal and conservative frames. They need to create words that reflect their ideas.

On the other side of the political fence, conservative political scientist Frank Luntz (2003) specializes in helping conservatives frame their spoken discourse to create the greatest appeal possible — what he called "message development" (pp. 131-135). Luntz was responsible for much of Newt Gingrich's 1994 "Contract for America," and more recently he guided conservatives on the strategic use of such terms as "war on terror" instead of "war in Iraq" and "climate change" instead of “global warming." What Lakoff called "frames," Luntz $(2002,2004)$ named "contexts"- ways to repackage positions so they carry more political currency.

Some have criticized Luntz's $(2002,2004)$ message development strategy as misleading or even immoral. The National Environmental Trust (2003) maintains www.luntzspeak.com, a Web site devoted to exposing and critiquing the Luntz messaging strategy. Despite such criticism, politicians have taken Luntz's advice to heart, and evidence of his influence and success are increasingly apparent. At the 1998 unveiling of the Council of Republicans for Environmental Advocacy, founder Gale A. Norton argued that public lands should support "multiple use," a Luntz-influenced context meant to suggest that such lands might be used for their resources in addition to being protected for wildlife (Booth, 2001). In 2001, the Interior Department passed a policy allowing local authorities the ability to exercise right of way for roads across federal lands (Cart, 2003). The policy did not automatically allow local municipalities to bulldoze and pave remote country, but it did recontextualize public lands as areas in which commercial activity might have a future place. Frames or contexts are not merely theoretical structures for intellec- 
tual navel gazing; they are operational models that are actively influencing public policy.

\section{POLITICAL VIDEOGAMES}

There are many precedents for commercial games that carry political messages. Well-known designer and video game pundit Chris Crawford's (1985) classic Balance of Power is often cited as the first political game in which diplomacy outweighed brute force. In the game, the player uses treaties; diplomacy; international espionage; and, as a last resort, military force to manage a world in the throes of the cold war. In an early example of game-based political expression, Crawford imbued his own worldview into the game play. Inciting a nuclear war caused a most grave lose condition in the game-a black screen imprinted with plain white offering a dour report of the player's outcome, "You have ignited a nuclear war. And no, there is no animated display or a mushroom cloud with parts of bodies flying through the air. We do not reward failure." Larry Barbu's (1991) cold war sim Crisis in the Kremlin followed in the tradition of Balance of Power, challenging the player to stay in power and to prevent the Soviet Union from dismantling. In 1990 two games were created that explored environmental issues. The first and more well-known was Maxis's (1990) Sim Earth: The Living Planet, a game adaptation of James Lovelock's Gaia Hypothesis-the theory that the earth functions as a continuous system for all life rather than a vessel for specific forms of life. In Sim Earth, the player nurtures single-cell organisms into capable complex organisms with intelligence enough to leave the planet. Pollution, disease, and global warming are among the obstacles that stand in the way. The second, more obscure environmental game of 1990 was Chris Crawford's (1990) environmental follow-up to Balance of Power, called Balance of the Planet, and it was released that year on the first celebration of Earth Day. The game offered a model of the earth's ecosystem, and a much more detailed one than Sim Earth. Crawford constructed some 200 individual environment factors such as lung disease, coal use, and coal tax-all of which were interconnected in a complex chain of causes and effects. Instead of manipulating the physical environment itself, as in Sim Earth, in Balance of the Planet the player manipulates social response to environmental conditions. For example, lowering the coal tax increases coal use, which in turn increases lung disease caused by coal pollution. In addition to changing environmental incentives, Crawford also allows the player to adjust the formula inputs used to calculate the results themselves. For example, a player can ratchet down the effect of coal-burning energy on lung cancer, effectively reducing the coupling between that particular cause and effect.

In addition to these early examples of politically charged commercial games, increasingly larger numbers of independently created games about political is- 
sues have cropped up on the Internet. Gonzalo Frasca (2003) launched www.newsgaming.com, a Web site to host games about current events. Frasca called newsgames a merger of video games and political cartoons and offered a first example of such a one, September 12. The reader is referred to my lengthy discussion of the game elsewhere (Bogost, 2006), but the general theme of September 12 is noteworthy for its unabashed bias. In the game, the player controls a missile crosshairs aimed at an anonymous middle-eastern town. Both innocent citizens and terrorists scurry around the town, and the player is faced with the problem of what to do about the terrorists. Although the latter effect no actual terrorist activity during game play, their threat is implied. If the player chooses to fire missiles, after a small launch delay a huge explosion destroys the area underneath the crosshair, and also a great deal of the surrounding area, including any people unfortunate enough to have been in the vicinity. When the player's missiles kill innocents, nearby citizens crowd around and mourn over the bodies before turning into terrorists themselves. The game's rules enforce a particular perspective: Violence begets more violence, and the nonprecision weapons of American "precision warfare" bear significant consequence in the form of innocent lives lost. Another pacifist game released in the aftermath of the September 11th terror attacks was Antiwargame (On, 2001), created by former Ars Electronica Golden Nica winner Josh On and his artist collective Futurefarmers. Antiwargame offers a simulation dynamic depicting the bind between homeland politics and foreign war.

These precedents are but a few of the previous commercial and independent games that have addressed political problems. But a major shift in the subgenre of political video games took place in 2004. In addition to becoming the year of an American political divide, 2004 was also the year when political video games became legitimate. For the first time, candidates and party groups created officially endorsed games to bolster their campaign for U.S. President (Bogost \& Frasca, 2003; Republican National Committee, 2004), U.S. State Legislature (Bogost, 2004b), U.S. Congress (Bogost, 2004a), and even President of Uruguay (Frasca, 2004). As the worlds of political message strategy and political videogames gain momentum, an opportunity arises for each to inform the other. As videogames become a part of endorsed political speech, they will become more tightly integrated with existing strategies for political discourse.

But Frank Luntz's (2002) contextual message development and George Lakoff's $(1990,1996)$ framed conceptual systems both define strategies for spoken or written political rhetoric. As such, these methods may be inappropriate for videogames, in which the main representational mode is procedural rather than verbal. The remainder of this article offers an approach to analyzing political rhetoric in videogames intended to carry ideological bias, paying special attention to the work of framing as a procedural rather than verbal strategy. I argue for three ways games function in relation to ideological frames-reinforcement, 
contestation, and exposition-through examples of art games, political games, and commercial games.

\section{REINFORCEMENT}

Customary uses of language do have some place in videogame based political messaging. The GOP's second game of the 2004 campaign, Tax Invaders (Republican National Committee, 2004), is a replica of the classic arcade game Space Invaders (Taito, 1978), but players defend the country against John Kerry's tax plans instead of a swarm of descending aliens. The player controls the disembodied head of George W. Bush, which he or she moves from side to side along the bottom of the screen in place of the original game's space gun. The player combats potential John Kerry tax cuts, represented as abstract rectangles bearing the numerical value of the proposed tax. The player fires projectiles out of the top of Bush's head to "shoot down" the tax hikes and defend the country.

The game's implementation is extremely crude-so crude that when I first played it, I quickly dismissed its rhetorical power, assuming it to be as rudimentary as the game's primitive visual and programmatic execution. If left long enough, the taxes-aliens pass over the player and off the bottom of the screen. And the blue "shields" - a critical strategic tool in Space Invaders - are rendered impotent in Tax Invaders. They seem to have been placed merely for show, or perhaps the game's programmers did not have time to turn them into active protective barriers. The game play itself amounts to a three-level long barrage of counter-tax projectiles. But since this original experience I have revisited the game, and I am now convinced that it represents one of the most sophisticated examples of a rhetorical frame at work, not just in videogame form, but anywhere in contemporary political discourse.

Within the game, written text contextualizes the player's actions. The copywriting enacts logic familiar to both Lakoff (1996) and Luntz (2002): It casts tax increases as an anthropomorphized enemy in itself-a thief against whom you must defend yourself. The game's opening text announces, "Only you can stop the tax invader," and it invites the player to "Save the USA from John Kerry's tax ideas." Lakoff argued that such language reflects an underlying logic at work in conservative politics - that citizens know what is best for themselves and that material success is moral and should not be punished. Conservatives, he suggested, conceptualize theft as a metaphor for taxation. The language that literally frames the game conforms to this metaphor; the player is contextualized as a force of good, "stopping" taxes and "saving" the country from them. Tax Invaders extends the verbal metaphor of "taxation as theft" to the tangible plane.

Released in March 2004 at the height of the second Gulf War, some might find it surprising that the GOP would choose to publish a depiction of George W. Bush 
shooting anything. But within the verbal rhetoric of conservative politics, taxation is a "battle" to be waged. Lakoff argued that, from the conservative perspective, tax increases are never proposals to improve the general social good, but always threats on the part of the government to steal what does not rightly belong to them. When someone breaks into your home, it is appropriate to brandish a gun. It is your property and you have to defend it. There is thus no political inconsistency in contextualizing tax opposition as hostility; indeed as violent hostility. In the context of Tax Invaders, George W. Bush's bullet-like projectiles are not akin to Army rifles wielded against innocent Iraqis, but rather to the policeman's sidearm wielded against a criminal.

A simple game such as Tax Invaders could be said to wear its rhetorical frame on its sleeve; indeed, the instantiations of conservative contexts are almost identical to their verbal counterparts. For example, we talk about politicians "shooting down" a measure in Congress. This figure even seems to function outside of the English language. In the aftermath of Hurricane Katrina in early autumn 2005, a German social minister used this verbal figure to attach President George W. Bush's handling of the crisis in New Orleans: "He ought to be shot down [gehört abgeschossen]." He later clarified that he meant the statement "in the political sense" (Reuters, 2005). The idea of a legislator "shooting down" a tax hike proposal is thus extremely plausible; the game just makes such a verbal frame materially manifest.

But Tax Invaders takes the metaphor beyond even visual rhetoric. One could imagine a political cartoon that literalized the verbal metaphor of legislation as battle. One side might throw out proposals for new laws or candidates for official posts that the opposing side would view as assaults rather than propositions, on which they would then open fire. Such a cartoon might effectively illustrate one party's unwillingness to consider the other's potentially legitimate proposals, for example. Such a cartoon would illustrate the verbal metaphor, rendering that metaphor into its visual equivalent. Tax Invaders frames the metaphors of its rhetoric even further-as embodied activities. Bush (and by extension the player) fires projectiles at the tax cuts, representing the metaphor of tax hikes as enemy threat. No matter the player's political perspective. To play the game at all he or she must step inside the skin of the taxation opponent, viewing taxes as a foreign enemy-in this case the most foreign enemy, a wholly other enemy whose very name means "otherness" itself: the alien.

Thus although Tax Invaders does little to represent actual tax policy, it frames tax policy in a way that reinforces a conservative position. The short text descriptions that bracket the game do bear a striking resemblance to verbal rhetoric used elsewhere in conservative politics. That resemblance should come as no surprise, because experienced conservative communication personnel probably penned the lines. But this verbal language remains largely imperceptible to the player; its function as metaphor is hidden to a public mired in their own familiarity with those 
metaphors. More surprising is the game's remarkable translation of the frame of taxation as theft from verbal to procedural form. The GOP authors of the game may not have had such a high-minded goal as to adapt their Luntz-style verbal rhetoric into computer code. Instead they likely took advantage of the resonance between this particular verbal metaphor and an existing, well-seated videogame mechanic (firing projectiles at things). Better yet, the GOP was able to find an existing game with a suitable, adaptable mechanic and, better still, a game with tremendous cultural currency, such that its constituency would find the game immediately approachable. After all, Space Invaders was first released in 1978, making it a good fit for voters in their 40s and 50s who would remember playing the game in arcades, as well as younger voters who could not have escaped Space Invaders' cultural wake.

George Lakoff (1996) argued that the conservative worldview holds the wealthy up as model citizens because they have worked hard and achieved success at their own hands, rather than from relying on tax-funded social programs. Conservatives view taxation as punishment, and in Lakoff's words, "that makes the federal government a thief" (p. 189). The political right views liberals' inclination to think of taxes as civic duty or even payment for government services as misguided: In the case of civic duty, conservatives see no obligation to contribute to the general assistance of the citizenry as a matter of principle. In the case of payment for services, conservatives point out that citizens do not have a choice to "purchase" the services funded by tax dollars. And furthermore, conservatives suggest that the government has a bad reputation for running ragged, primarily because it has no profit motive to drive efficient management, as would a business. Lakoff convincingly showed that opposition to taxation is fundamental to conservative politics because it underwrites so many other conservative positions. This includes things such as the drive to privatize government, turning poorly run federal and local services into well-run businesses with profit motives; the drive to reduce or eliminate social services in favor of strengthening backbone and enforcing personal responsibility as the primary factor in a thriving citizenry; the belief that people are fundamentally driven by reward and punishment; and taking away hard-earned cash from personally responsible citizens to give it to the irresponsible stinks of injustice.

Tax Invaders is an example of the reinforcement of an ideological frame. Typical political discourse would invoke the metaphor of taxation as theft or legislation as battle through verbal or written speech. For example, a politician might vow to "strike down new tax proposals" or warn that he or she might "return dollars stolen from Americans through unjust taxes." But Tax Invaders draws attention to the correlation between war and taxation, taxation and enemy threat, and taxation and theft. As a matter of cultural practice, alien invasions are tightly tied to theft. Alien abduction in the vein of The X-Files (Carter, 1993) is perhaps the best example, but alien invasions from The War of the Worlds (Wells, 1898) to Independence Day 
(Emmerich, 1996) all depict the aliens as malevolent agents bent on stealing the very planet Earth from its inhabitants. There is perhaps no more effective metaphor for theft than alien invasion.

Verbal or written rhetoric relies on our intrinsic experiences with metaphor as fluent speakers of a language. When listening to a politician on the soapbox, most of us would not even make note of the metaphors of theft and battle. The insight and utility of Lakoff's (1996) work on metaphor spoke to the ideology of the spoken word: Its logic must be exposed as a platform for the way we think, because it is not immediately obvious that conceptual metaphor underlies what we say and write. Tax Invaders not only makes its argument from within the conservative frame on taxation, but also it explicitly draws attention to the frame itself. The rules of the game-aliens descend continuously, the player character combats them before they reach the bottom-stand as symbolic structures of a higher order than natural language. These procedural metaphors operationalize the figures of the verbal metaphor into a functional system whose very function represents the desired position. Here the battle is both metaphoric and material. The player actually does battle against taxes, in a literal sense. I have called the general, procedural representation of abstract concepts unit operations (Bogost, 2006). Tax Invaders presents a set of unit operations for the conservative frame on taxation itself. Whereas verbal rhetoric invokes the frame (or context, to use Luntz's word) without acknowledging that the frame even exists, let alone structures the rhetoric, procedural rhetoric depicts the frame itself in a tangible form. Tax Invaders offers an unusual view onto the conservative frame for tax policy itself. In playing the game, the player is encouraged not only to consider and reaffirm a conservative position on taxation, but also to consider and practice using a conservative frame for that position.

A game such as Tax Invaders can thus serve opposing political purposes. For conservatives it reinforces the notion that taxes are an invasion and we need to "wage war" against them, as we would against alien invaders. This sort of rhetoric would be much more difficult, or at least more inappropriate, to enact on the soapbox. On the public pulpit, grandstanding politicians rely on the perlocutionary rather than illocutionary effect of their rhetorical frame. In speech act theory, an illocutionary act carries propositional content that the utterance expresses literally. A perlocutionary act carries an effect that is not expressed in the utterance, such as persuasion (Austin, 1962; Searle, 1969). Tax Invaders offers the unique ability to convert perlocution into illocution. Instead of using verbal frames, the GOP has made the symbolic underpinning of their rhetorical context manifest in the game rules itself: a procedural rather than a verbal rhetoric. In essence, Tax Invaders is a lesson in how to think about tax policy as a conservative would. The game says, "Think of taxation as an invasion meant to harm you" rather than saying, "We must fight against tax increases." For liberals, Tax Invaders reinforces the conservative frame on taxation, forcing such players 
to enact the conservative position that taxation is a theft rather than a contribution to the common social good. Playing the game critically might assist liberals in orienting their frame in opposition to that of conservatives. The game's crudeness only underscores how foundational the metaphor of taxation as theft is for conservative politics and, therefore, how challenging opposition to it may prove. Each perspective is one side of the same coin. Although Tax Invaders offers only a very rudimentary treatment of tax policy, it offers a more sophisticated reinforcement of a conservative rhetorical frame on tax policy.

\section{CONTESTATION}

Tax Invaders mounts its argument partly from the verbal register (the text inside the game) and partly through macroscopic imagery (George W. Bush as hero and the descending taxes). Although it does depict the rules that constitute the conservative frame on taxation, it borrows those rules entirely from another videogame. To further understand the way frames and ideological bias function in videogames, we must look at how the interactions of new rules create similar frames as verbal political rhetoric.

In French artist Martin Le Chevallier's (2000) installation game Vigilance 1.0, players seek out deviants on surveillance screen-like sections of an urban environment. The game screen is divided into small squares, each of which displays a different segment and scale of the detailed city. Citizens traverse the environment, executing tasks typical of everyday urban life, such as shopping at the supermarket or relaxing in a park. The player's task is to watch these screens and identify improprieties ranging from littering to vagrancy to prostitution. Armed with a small circular cursor, the player must constantly scan the environment, pointing out infractions by clicking on offenders. For each success, the player is rewarded with points proportional to the severity of the offense (e.g., littering is valued at 1 point and prostitution at 5). Erroneous identifications cost the player points for "defamation." The game is programmed to increase or decrease social problems in proportion with the player's success at responding to them. With every offender that passes by unnoticed, the more depraved the society becomes, and vice versa.

Vigilance's rules are incredibly simple. The player can censure citizens; successes are rewarded and failures punished; and for each success the society becomes more pure, whereas for each failure or omission more base. It is a game about surveillance disguised as one about moral depravity, the 16 rectangular segments of the screen akin to a security guard's video monitors. The player's "vigilance" quickly devolves into its own perversion-that of unfettered surveillance.

Because the game creates a positive feedback loop for depravity in the society, any attempt on the player's part to cease his or her vigilant oversight creates more corruption, reinforcing the need to monitor. By forcing the player to see the conse- 
quences of the metaphor of vigilance as comprehensive regulation, the game challenges the ideological frame it initially represents. The game's purpose is not to promote surveillance nor moral purity, but to call such values into question by turning the apparently upstanding player into one of the depraved whom he or she is charged to eliminate.

On first blush, the game seems to reinforce the ideological frame of vigilance as safeguard. The game supports this sentiment through its rules, which provide positive feedback for increased surveillance. But over time, the player comes to realize that his or her adopted role as overseer is no less perverse than the game's abstract representations of moral depravity - prostitution, vagrancy, and zoophilia. The game then affords the player a variety of ways to interrogate this challenge.

The game's reinforcement system encourages players to calculate one offense in terms of another: five litterbugs for every prostitute. The notion of equivalence between actions and their consequences evokes another metaphor for political thought—what Lakoff (1996) called keeping the moral books. In Lakoff's view, we conceptualize well-being as wealth. Changes to our well-being are thus akin to gains and losses. Lakoff characterized this metaphorical understanding of morality in terms of financial transactions. Individuals and societies alike have "moral debts" and "moral credits" that must sum to zero. Moral accounting implies the need for reciprocation and retribution; good actions must be rewarded, and harmful ones must be punished. That punishment might include restitution, which can in turn take many forms, from contrition to prison. When we speak of criminals who have completed their sentences, we often say that they have paid their debt to society. In a moral system of this type, "the moral books must be balanced" (Lakoff, 1996, p. 46).

In contemporary U.S. politics, a fair society is generally conceived as one in which an authority keeps track of the moral books and does the moral accounting. This metaphorical Chief Financial Officer takes many forms, from the courts to the police to the parent at the cookie jar. Lakoff (1996) identified one common attitude toward public justice that stems directly from the concept of moral accounting. He called this model "procedural fairness" or "the impartial rule-based distribution of opportunities to participate, talk, state one's case, and so on" (p. 61). Here the term "procedural" refers to the invocation of legal rules that determine what behavior is allowed and prohibited in a society.

In one version of procedural fairness, the failure to account for improprieties puts the books out of balance. Vigilance allows the player to experiment within this frame. The game deploys an arithmetic algorithm to control the amount of depravity to feed back into the system. Identifying more perverse acts increases the score more rapidly. For example, public drunkenness is worth 2 points and abandoned trash 1 point. The player could choose to target only the most egregious acts as a kind of strategy for more efficient moral sanctity. But while watching for public urination or prostitution, many more low-level acts will already have begun to 
cause the society to spiral into further chaos. The frequency of low-level acts is higher, giving players an opportunity to locate and identify more litterbugs and drunkards for every prostitute, public urinator, or pedophile.

At the same time, the game forces the player to recognize the consequence of blind moral accounting. When one pedophile equals three drunkards equals six litterbugs, both the acts and the contexts for those acts are occluded. As Lakoff (1996) pointed out, "rule-based fairness invites dispute over how impartial the rules really are" (p. 61). When the player of Vigilance clicks indiscriminately on vagrants and violent criminals alike, he or she is forced to think of each as a variety of the same, underlying moral depravity. The game does not afford the player the ability to consider the impartiality of the rules of surveillance and, thus, invites reflection on the nature of each particular act. Why is the drunkard drunk? Is he or she unaware of social convention? Is he or she mentally ill and in need of assistance? Has he or she suffered a personal tragedy and is calling out for empathy?

I argued previously that simulations exist in the gap between rule-based representations and a user's subjectivity (Bogost, 2006). Vigilance thus provides a variety of player-configurable lenses through which to consider and reconsider the ideological frame of vigilance as inviolability. As the player identifies more and more deviants, Le Chevallier (2000) intended the game to slowly but progressively change the focus from balancing the society's moral books to questioning procedural fairness as a legitimate strategy for running a society. Most explicitly, Vigilance attempts to identify such moral bookkeeping as a disturbing panopticon. But the game also challenges other aspects of the frame of justice as balanced moral books: moral depravation and criminality as a slippery slope of interrelated behaviors, and social justice as removal or incarceration rather than social support and reformation.

\section{IMPLICATION}

Both Vigilance 1.0 and Tax Invaders could be seen as special cases-games created explicitly with ideological bias in mind (one for artistic reasons and one for political reasons). Commercial games may be less deliberate in their rhetoric, but they are not necessarily free from ideological framing. Such games may imply complex procedural rhetoric with or without the conscious intention of the designers. Although the rhetorical intentions of the GOP or artists such as Le Chevallier (2000) are palpable, the relative obscurity of those games restricts their influence. But procedural rhetoric in commercial games-the most successful of which easily sell between 5 and 10 million copies - trade forthrightness for authority. And that authority can occlude the ideological frames popular commercial games operationalize, rendering them implicit and in need of critique. 
In Grand Theft Auto: San Andreas (Rockstar Games, 2004), players enact the life of an early 1990s Los Angeles "gangbanger." Whereas previous iterations of the series favored stylized representations of historico-fictional times and places (Rockstar Games, 2001, 2003), San Andreas takes on a cultural moment steeped in racial and economic politics. Rather than taking on the role of an organized criminal, the player is cast as CJ, an inner-city gangster. Grand Theft Auto's use of large navigable spaces and open-ended game play have been widely cited and praised, but in San Andreas open game play, expansive virtual spaces, and the inner-city characterization collide to underscore opportunity biases.

San Andreas added the requirement that $\mathrm{CJ}$ eat to maintain his stamina and strength. However, the only nourishment in the game comes from fast food restaurants (chicken, burgers, or pizza). Eating moderately maintains energy, but eating high fat content foods increases CJ's weight, and fat gangsters cannot run or fight very effectively. Each food item in the game comes at a cost, and the player's funds are limited. Mirroring real fast food restaurants, less fattening foods such as salad cost more than high-calorie super meals. The dietary features of San Andreas are rudimentary, but the fact that the player must feed his or her character to continue playing does draw attention to the material conditions the game provides for satisfying that need. This subtly exposes the fact that problems of obesity and malnutrition in poor communities can partly be attributed to the relative ease and affordability of fast food.

Evidence has suggested that citizens on fixed incomes, such as students and the working poor, have easiest access to fast food, and as a result of this convenience they eat more of it. Fast food has even penetrated our very health care infrastructure. More than one third of top U.S. hospitals have a fast food outlet on premises (Markel, 2003). Nutritionist Marion Nestle (2002) devoted much of her career to identifying the relation between nutrition, food policy, and food industry marketing. Obesity, argued Nestle, replaced dietary insufficiency as the major nutritional problem in the United States in the 100 years since the turn of the 19th century (Nestle, 2002). Nestle traced the connections between obesity and a food industry intent on increasing food consumption to drive profits. One major contributor to the problem is portion size. According to Nestle, Americans consume larger portions of over one third of all foods, including bread, french fries, and soft drinks. The familiar "super size" fast food option is one example, immortalized in Morgan Spurlock's (2004) Oscar-nominated documentary Super Size Me. Today, Americans worry about avian flu and chemical weapons attacks, but we also stuff ourselves with high-sugar Krispy Kremes; cholesterol-raising hydrogenated oils; and high-fat, low-nutrient foods. Fad diets such as Atkins focus on quick results at the cost of long-term health. Nestle and Spurlock's work underscored the same basic principle: Obesity and other threats to public health are at best encouraged, and at worst directly caused by the food market itself.

The tension between personal responsibility and social forces is related to another of Lakoff's (1996) metaphors for political thought—what he called "moral 
strength" (p. 74). Moral strength entails the courage to stand up to both internal and external evils, and it is fundamentally related to will. In Lakoff's model, moral strength comes from self-discipline and self-denial. The disciplined person is strong, and therefore moral, whereas the man who cannot stand up to temptation is weak, and therefore immoral. Lakoff explicitly linked moral strength with asceticism. Self-indulgence and "moral flabbiness" are the domain of the morally weak (p. 74). Moral strength is fundamentally a conservative political frame that stands in contrast to the liberal equivalents of empathy and nurturance (Lakoff, 1996).

It is no accident that flabbiness would come up in a discussion of moral strength. In the conservative frame, obesity and poor health are tied to self-control or the ability to assess and resist the internal temptation to eat the wrong food, or to overeat. In such a worldview, a problem such as obesity has nothing to do with the food industry Nestle (2002) and Spurlock (2004) renounced. The executives at fast food corporations and the proprietors of their franchises are fulfilling another aspect of conservative moral strength. Businesspeople are morally strong agents with self-discipline enough to work hard and earn material success (Lakoff, 1996). The apparent conflict between the morally strong entrepreneur and the morally weak overeater are not contradictory for conservatives. The latter are conceived as lesser citizens by the morally strong conservative, and gaining material advantage at their expense only further underscores both the moral and material superiority of the former. In Lakoff's own words, the conservative frame of moral strength "rules out any explanations in terms of social forces or social class" (p. 75).

That fast food restaurants represent the only path to sustenance in Grand Theft Auto: San Andreas, and that such sustenance is required to progress and achieve goals in the game suggests two possible interpretations. On the one hand, the fact that food comes only from fast food joints implies a social condition more like the critique Nestle (2002), Spurlock (2004), and others have mounted against the fast food and packaged foods industries. For the less-fortunate in particular, the cheap, factory-style, high-fat, low-nutrient food of the burger joint or taco hut represents the easiest and most viable way to fill a grumbling stomach. When these establishments try to provide more healthful meals, such as salads, they come at a cost premium. As I write this in late 2005, a "premium salad" at McDonalds costs $\$ 4.99$, whereas a Big Mac costs \$2.59. ${ }^{1}$ Under this interpretation, San Andreas's enforcement of fast food eating serves to expose the social forces that drive the poor and working-class residents of the inner-city to consume fast food habitually. The game even allows the player to reap the health detriments of a fast food diet in the form of lost stamina and lost respect (see the following for more on this point).

\footnotetext{
${ }^{1}$ The salad, when eaten with the dressing it comes with, totals nearly as many calories as a Big Mac. Some configurations of the salad with dressing even offer more grams of total fat than a Big Mac. See http://www.mcdonalds.com/app_controller.nutrition.index1.html
} 
Even if the player does not play enough (or eat enough) to make CJ turn from a lithe youth into a portly one, the game's insistence that the player eat only at fast food restaurants draws attention to the social reality of poverty and its related health effects. Players of San Andreas might leave the game and make new observations about the world around them, and how social opportunity and disclosure often overshadows the issue of self-restraint.

On the other hand, the game seems to allow the player to overcome the social conditions of poverty and poor nutrition through hard work-a textbook example of moral strength. No matter what the player eats in the pizza place or the chicken hut, he or she can always build a ripped chest and six-pack for CJ by working out constantly in the game's gym. Furthermore, the more "healthful" salad meals at the restaurants cost more money, and the player earns money primarily through the "work" of playing the game. To be fair, that work is almost exclusively limited to violent crime, a topic that I return to shortly. Despite its apparent support for nutrition as a condition of social station, San Andreas allows the player to overcome that condition through relatively simple, if sometimes tedious, work and exercise. Such rules might tilt the game toward a more conservative frame-one in which discipline and hard work can overcome material conditions.

The game's use of open-ended virtual spaces presents a less ambiguous frame for social class, race, and criminality. San Andreas intricately recreates representations of three huge cities (the equivalents of Los Angeles; San Francisco; and Las Vegas, NV) along with rural spaces in between. CJ has recently returned to his hometown neighborhood (the San Andreas equivalent of Compton in Los Angeles) to avenge his mother's death. The player can customize CJ's clothes to some extent and, of course, steal nice cars for him, but he remains a Black youth from Compton wearing gang-associated paraphernalia. Thanks to the immense simulated space of the city, the player can travel from neighborhood to neighborhood, and the buildings, scenery, vehicles, and people adjust accordingly. But something remains the same everywhere in San Andreas, from its Compton to its Beverly Hills: No matter the location, the game's non-player characters respond to your semiautomatic-toting, do-rag wearing Black "gangsta" character in roughly the same way.

Although major technology challenges impede the development of credible character interactions in an environment as large-scale as San Andreas and its surrounds (see Mateas \& Stern, 2002), the game makes no effort to alter character behavior based on race, social standing, or location. Bumping into a leggy blonde on the equivalent of Beverly Hills' Rodeo Drive elicits the same anonymous outcry as would jostling a drug dealer on Compton's Atlantic Drive. When mediated by the game's inner-city context, its procedural interaction of space and character creates a frame in which the player's street gang persona does not participate in any historical, economic, racial, or social disadvantage. The aggregate procedural effects in San Andreas thus expose an ideological frame, and perhaps a surprising one. 
Lakoff (1996) argued that the conservative frame for crime is an extension of the "strict father" model of seeing the world. The strict father disciplines his children and acts as a moral authority. Through this example, he instills discipline and self-reliance. Self-reliant, morally disciplined adults make the right decisions and prosper. Morally depraved adults do not deserve to prosper and may even be dangerous. Lakoff contrasted the conservative strict father with the progressive "nurturing parent." Unlike the strict father, the nurturing parent believes that support and assistance helps people thrive, and that people who need help deserve to be helped. Nurturing parents reject self-discipline as the sole justification of prosperity and allow for economic, cultural, or social disadvantages that might suggest some people deserve even more assistance.

By avoiding interactions across the socioeconomic boundaries of the game's virtual space, San Andreas is implicated in a logic similar to the conservative frame on crime. If the non-player character's logic were to admit to cultural and economic disadvantages as factors that mediate interaction between characters, it would also have to admit that such factors are external to CJ (the player's character) and thus attributable to something outside CJ's character and self-discipline. As in the case of nutrition, from a frame of moral strength CJ's criminal behavior can be explained only by a lack of self-control and self-discipline. Any morally upstanding young man would find a legitimate job and earn his way off the street without resorting to criminality. But interestingly, the game turns this frame in on itself. To succeed in the mission-based story of San Andreas, the player effectively builds a sizable, if illegitimate, business of thug activities, based on a staple of drive-by shootings and armed robbery. Yet the game is a veritable rags-to-riches story. As the game starts, CJ is returning to Los Santos from Liberty City (the home city of Grand Theft Auto III), where he had fled the gang-ridden streets of his youth, presumably as a reformed man. He returns only to bury his mother, another victim of gang violence, and gets caught up in reclaiming his old neighborhood from the rival gangs who are dismantling it. As CJ, the player must build "respect" between both his or her own gang members and rival gang members, eventually earning their trust and constructing an ever-larger gang of followers.

The addition of respect signals an unusual perversion of the traditional, conservative concept of moral authority. On the one hand, CJ's life on the street bears a striking resemblance to that of the political conservative. He takes responsibility for his family and takes it on himself to build a new life of material wealth and personal safety. His authority demands respect from others, and those whose respect he demands stand subordinate to him. His own personal self-discipline even contributes to this respect. A well-padded $\mathrm{CJ}$ who eats too many burgers and does not work out earns less respect than a muscle-ripped CJ. On the other hand, CJ earns such respect entirely through felonious behavior. He acts with a similar underlying value structure as the ideal conservative, but uses lawless rather than lawful material production as his medium. This inversion of the typical conservative frame 
could be read as a satire - the very same rules of behavior produce a very different outcome.

But outside of the game's tightly woven mission-based story line, Grand Theft Auto: San Andreas implies clear support for the metaphor of crime as decadence. Despite its purported open-endedness, San Andreas offers incentives to play its missions, and thus incentives to engage in criminal behavior. Although the story does question whether gang members have legitimate moral options-at the start of the game CJ is set up by a corrupt cop and sent on the run-once outside of the mission architecture, the game has no procedure in place to mediate character interactions. Notably, the open-ended game play reorients the player back toward the missions. The game will not unlock areas beyond Los Santos unless the player reaches key points in the missions. Despite its narrative gestures toward subverting the gang as a possible social adaptation, the game situates the story missions as small accidents in the broader urban logic. As the player exits the open urban environment and reenters the missions, he or she does so willingly, and not under the duress of a complex historico-social precondition. This rhetoric implicitly affirms the metaphor of criminal behavior as moral depravity.

Whether San Andreas's creators intended the game to support or critique contemporary conservative American ideological structures is an open question. But the fact that the game has been so universally reviled, not only by the "values-oriented" conservative right but also by pillars of contemporary centrist politics, such as senators Hillary Clinton and Joseph Lieberman, suggests that neither side has actually played the game. How surprised would the conservatives be to find that a group of Scottish game developers may have placed tens of millions of copies of conservative political rhetoric in the waiting hands of contemporary American youth. This includes many inner-city youth who would normally be predisposed to oppose Republicans' pro-business, antisocial program stances. And how surprised might liberals be to find that they might have the perfect object lesson for counteracting conservative frames about poverty, class, race, and crime already installed on the nation's PlayStations. Even so, unexpected ideological frames similar to those implicated in Grand Theft Auto: San Andreas do not necessarily indicate that commercial developers have a hidden political agenda. For better or worse, it is much more likely that they are unaware that the procedural interaction in the game can imply a particular ideological stance. Market forces are unlikely to expose such failing as imprudence, and thus the task of unpacking ideology in games like San Andreas will become the work of the critic.

\section{DESIGN FUTURES FOR POLITICAL GAMES}

Politicians are already familiar with Lakoff's (1996) and Luntz's (2004) strategies on framing political speech, especially public speech. Those who wish to create 
videogames as endorsed or disruptive political speech will undoubtedly need to pay more attention to the use of context in such games. A shift away from verbal and toward procedural contextualization in such games will likely take longer. Lakoff (1996) argued that the central role in contemporary politics (and he has progressive politics in mind in particular) is to breathe new life into an otherwise bankrupt political discourse. This restructuring is necessary because citizens assume language and its carriers-from politicians to news media—are neutral. The public has little purchase on the "moral conceptual systems" that underwrite verbal and written political utterances themselves. Understanding a political position, argued Lakoff, "requires fitting it into an unconscious matrix of family-based morality" (p. 384). It is worth noting the urgent and somewhat desperate note on which Lakoff ended Moral Politics: How Liberals and Conservatives Think:

In short, public discourse as it currently exists is not very congenial to the discussion of the findings of this study. Analysis of metaphor and the idea of alternative conceptual systems are not part of public discourse. Most people do not even know that they have conceptual systems, much less how they are structured. This does not mean that the characterizations of conservatism and liberalism in this book cannot be discussed publicly. They can and should be. What requires special effort is discussing the unconscious conceptual framework behind the discussion. (pp. 387-388)

Lakoff (2004) called this process frame shifting. Perhaps the most promising future political role of videogames will serve to help citizens take on precisely this challenge. As procedural systems, videogames are the only medium of mass appeal across many ages, demographics, and social-ethnic backgrounds that rely on conceptual frameworks - rule-based interactions - as their core mode of signification. We do not find it surprising when films like Farenheit 9/11 (Moore, 2004) or television series such as The Daily Show (Smithberg \& Winstead, 1996) make explicit, outright attempts to change political affinity. This is not yet the case for videogames. But unlike consumers of film, television, books, and other linear media, videogame players are accustomed to analyzing the interaction of proceduralized logic as a part of the play experience. John C. Beck and Mitchell Wade (2004) called this process "going meta" (p. 167), and they argued that it is changing the way a whole generation raised on games approaches business problems. Although particular political interests have effectively colonized some media-liberals and documentary film, conservatives and talk radio, for example-videogames remain indefinite about their political bent. This situation underscores a promise and a threat. On the one hand, the medium of the videogame has not (yet) become attached to a particular worldview; thus welcoming all varieties of ideological frames. On the other hand, lessons from other media have suggested that the political groups with stronger media strategies effectively lock out other voices. The questionable success of liberal talk radio station Air America 
provides an instructive example. The left has been effectively banished from the airwaves because the conservatives became entrenched on them so much earlier. Although it is first an analysis of political discourse, George Lakoff's (1996) Moral Politics: How Liberals and Conservatives Think could equally be described as a scathing critique on the failure of liberal political discourse. Perhaps today it seems Pollyannaish to claim that videogames might offer the most salient locus for discussions of how we think about political problems. But in time, and not much of it in my view, we will wonder why it took so long to realize that games had been a part of public political discourse, all along. And when that time comes, it would be unfortunate for one set of political positions to have so colonized the medium as to taint it for dissenting opinion.

\section{REFERENCES}

Austin, J. L. (1962). How to do things with words. Cambridge, MA: Harvard University Press.

Barbu, L. (1991). Crisis in the Kremlin. [Computer software]. Alameda, CA: Spectrum Holobyte.

Beck, J. C., \& Wade, M. (2004). Got game: How the gamer generation is reshaping business forever. Cambridge, MA: Harvard Business School Press.

Bogost, I. (2004a). Activism: The public policy game. Atlanta, GA: Persuasive Games.

Bogost, I. (2004b). Take back Illinois. Atlanta, GA: Persuasive Games/Illinois House Republicans.

Bogost, I. (2006). Unit operations: An approach to videogame criticism. Cambridge, MA: MIT Press.

Bogost, I., \& Frasca, G. (2003). The Howard Dean for Iowa game. Burlington, VT: Dean for America.

Booth, W. (2001, January 8). For Norton, a party mission. The Washington Post, p. A01.

Cart, J. (2003, January 21). Bush opens way for counties and states to claim wilderness roads. The Los Angeles Times, p. 1.

Carter, C. (Director). (1993). The X-Files [Television series]. Los Angeles, CA: Fox.

Crawford, C. (1985). Balance of power. [Computer software]. Novato, CA: Mindscape.

Crawford, C. (1990). Balance of the planet. Author.

Emmerich, R. (Director). (1996). Independence day [Motion picture]. Los Angeles, CA: Fox.

Frasca, G. (2003). September 12. Montevideo, Uruguay: Newsgaming.com.

Frasca, G. (2004). Cambiemos. Montevideo, Uruguay: Frente Amplio Nueva Mayoria/Powerful Robot Games.

Lakoff, G. (1990). Women, fire, and dangerous things. Chicago: University of Chicago Press.

Lakoff, G. (1996). Moral politics: How liberals and conservatives think. Chicago: University of Chicago Press.

Lakoff, G. (2004). Don't think of an elephant: Know your values and frame the debate-The essential guide for progressives. New York: Chelsea Green.

Lakoff, G., \& Johnson, M. (1980). Metaphors we live by. Chicago: University of Chicago Press.

Le Chevallier, M. (2000). Vigilance 1.0. Helsinki: Kiasma Museum.

Luntz, F. I. (2002). Energy, preparing for the future. Alexandria, VA: Luntz Research Companies.

Luntz, F. I. (2003). The environment: A cleaner, safer, healthier America. Alexandria, VA: Luntz Research Companies.

Luntz, F. I. (2004). The best and worst language of 2004: Key debate phrases. Alexandria, VA: Luntz Research Companies.

Marinucci, C. (2004, November 7). In postmortem on Kerry bid, Dems seek clues to new life. The San Francisco Chronicle, p. A1. 
Markel, H. (2003). Fast food, obesity, and hospitals. Medscape Pediatrics, 5(2).

Mateas, M., \& Stern, A. (2002). A behavior language for story-based believable agents. IEEE Intelligent Systems, 7(4), 39-47.

Maxis. (1990). Sim earth. [Computer software]. Alameda, CA: Microprose.

Moore, M. (Director). (2004). Farenheit 9/11 [Motion picture]. Culver City, CA: Sony Pictures.

National Environmental Trust. (2003). Luntzspeak.com. Retrieved October 10, 2005, from http://www.luntzspeak.com

Nestle, M. (2002). Food politics: How the food industry influences nutrition and health. Berkeley, CA: University of California Press.

Nestle, M. (2003). Increasing portion sizes in American diets: More calories, more obesity. Journal of the American Dietetic Association, 103, 231-234.

On, J. (2001). Antiwargame. [Computer software]. San Francisco: Futurefarmers.

Republican National Committee. (2004). Tax invaders. Washington, DC: Author.

Reuters. (2005). Minister: Bush must be "shot down." Retrieved October 10, 2005, from http://www.cnn.com/2005/WORLD/europe/09/08/germany.bush.reut/

Rockstar Games. (2001). Grand theft auto III. [Computer software]. New York: Take Two Interactive.

Rockstar Games. (2003). Grand theft auto: Vice City. [Computer software]. New York: Take Two Interactive.

Rockstar Games. (2004). Grand theft auto: San Andreas. [Computer software]. New York: Take Two Interactive.

Schifferes, S. (2004a, November 3). Election reveals divided nation. London, UK: BBC News.

Schifferes, S. (2004b, November 3). What next for the Democrats. London, UK: BBC News.

Searle, J. (1969). Speech acts: An essay in the philosophy of language. Cambridge, England: Cambridge University Press.

Smithberg, M., \& Winstead, L. (Creators). (1996). The daily show [Television series]. New York, NY: Comedy Central.

Spurlock, M. (Director). (2004). Super size me [Motion picture]: Hard Sharp.

Taito. (1978). Space invaders. [Videogame]. Tokyo: Author.

Vanderbei, R. J. (2004). Election 2004 results. Retrieved October 10, 2005, from http://www.princeton.edu/ rvdb/JAVA/election2004/

Wallsten, P., \& Anderson, N. (2004, November 6). Democrats map out a different strategy. Los Angeles Times.

Wells, H. G. (1898). The war of the worlds. New York: Aerie. 